Ssciendo Studia Anglica Posnaniensia 56 (2021): 149-179

doi: 10.2478/stap-2021-0029

\title{
DEVELOPING INTERCULTURAL IDENTITY ON A SOJOURN ABROAD: A CASE STUDY
}

\author{
PAWEX SOBKOWIAK ${ }^{1}$
}

\begin{abstract}
This article reports on a longitudinal case study and gives first-hand accounts of the lived experiences of five Erasmus+ students from Turkey during their sojourn at a university in Poland and its impact on the students' individual identities. The research aimed to investigate students' learning experience at the host institution and intercultural adaptation, focusing on the transformative outcomes that the sojourn brought about in them. The framework used as a theoretical basis for the study was Kim's integrative theory of communication and cross-cultural adaptation. The theory claims that cultural adjustment is a function of an individual's development of social and personal communication competence in their respective environments. As a result of frequent meaningful interactions with cultural others, through meeting and overcoming multiple intercultural challenges, people are likely to develop intercultural personhood, going through three consecutive stages, i.e., stress-adaptation-growth (Kim 2008). The study outcomes show sojourning abroad as a rather positively valenced experience, contributing to participants' gaining knowledge about diverse cultures, the skills to cope with diversity and an increased willingness to interact with people from different ethnic backgrounds. The data revealed that the participants underwent, to a moderate degree, a cultural identity shift toward becoming more mindful, open-minded, self-other oriented, and inclusive toward diversity.
\end{abstract}

Keywords: Adaptation; intercultural experience; identity; sojourn abroad.

\section{Introduction}

Short-term residence abroad as an opportunity to develop language skills and encounter new cultures has a long tradition in language education (Bochner, Lin \& MacLeod 1979; Gertsen 1990; Stephenson 1999; Dweyer 2004; Deardorff 2006; DeKeyser 2007; Behrnd \& Porzelt 2012; Jackson 2015). One example of such an

1 Faculty of Law and Administration, Adam Mickiewicz University; ul. Wieniawskiego 1, 61712 Poznań, Poland; pawelsob@amu.edu.pl 
initiative undertaken in the European Union is the Erasmus+ program. The program enables students from member countries to spend part of their studies, usually a semester or two, as temporary sojourners in a foreign country, acquiring new language skills, as well as interpersonal and intercultural skills, alongside new academic knowledge (Banks \& Bhandari 2012). Research on the second language (L2) learning outcomes of study abroad has confirmed the expected broad linguistic gains in learners' L2 oral proficiency, especially in fluency, pragmatics, and vocabulary development (Magnan \& Back 2007; Collentine 2009; Hernandez 2010; Taguchi 2015). However, while some sojourners made meaningful progress when abroad, their achievements varied significantly, others made little or no progress at all (DeKeyser 2007). This might result from the fact that, as DeKeyser (2007: 214) puts it, "foreign language practice during study abroad is more limited than one may assume, in terms of quantity, as well as quality and in terms of input, output, interaction, and feedback". In the same vein, research revealed that such sojourns can have either a positive or negative effect on students' motivation to learn and use the L2, both while abroad and after their return home (Allen 2010; Kormos, Csizér \& Iwaniec 2014; Irie \& Ryan 2015; Du 2019).

Except for researching changes in L2 proficiency, scholars investigated the impact of sojourning on participants' personality, identity, and intercultural awareness (Jackson 2010, 2015; Kinginger 2009, 2013b; Tian \& Lowe 2014; Fang \& Baker 2017), highlighting students' growth in problem solving, selfdiscovery, and coping with diversity. Furthermore, the research documented difficulties students had with access to host communities and social networks in residence abroad, and their reluctance to invest time to start/develop relations and interact with locals (Vande Berg \& Paige 2009; Lou \& Bosley 2012). Sojourners often perceived their native language as a protective capsule where they could hide from the new cultural context by which they were surrounded (Wilkinson 1998). These findings debunk the deeply ingrained immersion myth; i.e., the conviction that study abroad automatically translates into sojourners' becoming more open and inclusive to diversity. On the contrary, international experience can be highly variable - students may return home more ethnocentric and less willing to interact with people who come from different linguistic and cultural environments (Vande Berg 2007; Jackson 2015). For example, there is evidence that intercultural contact itself does not directly change the attitudes of an individual toward otherness, but what contributes to such a change is their willingness to mediate the contact experience (Van Dick et al. 2004).

The majority of published research on developing intercultural identity was carried out among international students in the US (Kim 2015) and China (Tian \& Lowe 2014), where sojourners could freely interact with the host community since English was either the mother tongue for the majority of locals (the US) or it was used extensively in education (China). The present study, 
however, investigates the experiences of students from Turkey during their residence in Poland. The sample interacted with both locals and other international students in English, the shared language, non-native for all the mentioned groups, which affected interaction and relationships in many ways. Since insufficient research has been done in such a context, the current publication seeks to bridge this gap and, thus, is timely.

\section{Literature review - theoretical grounding}

The theoretical underpinning of the current research is Kim's integrative theory of communication and cross-cultural adaptation, which assumes that each person is part of an open system of reciprocal influences and interfaces with the surrounding environment, incorporating divergent cultural elements that are encountered (Kim 1988, 2001, 2005, 2008, 2015). Similarly to poststructuralist scholars (Davis \& Harré 1990; Hall 1992, 1997; Bhabha 1994; Menard-Warwick 2005; Morgan 2007), Kim believes that identity, in general, and cultural identity in particular, are socially constructed, in and through discourse. Whenever the system is disrupted, people are motivated to restore order to reduce stress they experience. In response to being exposed extensively to cultural diversity, they modify their identities, i.e., accepted behaviours - "what they do, how they make sense of what they do, and how they make choices of what they do" (Chen 2010: 489). In this way they try to reestablish psychological health and functional fitness, i.e., the ability to participate comfortably in daily life activities in the host culture. Although Kim's theory originally explains cross-cultural adaptation in a completely strange environment, which is not the case of sojourns, both situations bear some baseline similarity (Pitts 2016), thus it can be applied to studying abroad.

Kim (2005) claims that at the center of the transformative and adaptive processes connected with staying in an unfamiliar environment is communication. Only social engagements (face-to-face conversations) with representatives of unfamiliar ethnic and cultural backgrounds allow for gaining cultural knowledge, experience, and skills, and lead to intercultural growth. In addition, intercultural encounters have the potential to transform individuals, i.e., their values, and worldviews, and change their perception of self and others, prompting them to cease looking at people through largely mono-cultural lenses. Contrary to this, limited or constrained communication with the host culture hinders cross-cultural adaptation.

Likewise, language is constructed in interactions in a foreign language classroom, where students establish a variety of relationships, not only realistic, but also imagined; i.e., those they may hope to build (Anderson 1983). Every time language learners (or sojourners) use the target language, they are not only 
exchanging information, but "they are also organizing and reorganizing a sense of who they are and how they relate to the social world. They are engaged in identity construction and negotiation" (Norton 2013: 4), hence, identities can be understood only if they are explored as continually being formed, negotiated, and reformed in social contexts (Ivanič 1998).

Cultural identity, an umbrella term covering a range of concepts such as ethnic, linguistic, racial, gender, and class identity, according to De Vos (1990: 14), provides "a sense of common origin, as well as common beliefs and values" (1990: 204). It also helps individuals identify as belonging to a particular cultural group. Kim postulates replacing the term by intercultural identity - "an openended, adaptive and transformative self-other orientation" (Kim 2008: 364). In her view, such conceptualization more appropriately mirrors our world of increasing interconnectedness, where "the self-other" boundaries are more and more blurred, and individuals on a daily basis encounter situations that deviate from their familiar cultural scripts. Kim claims that intercultural identity can be developed only through experiencing cultural diversity in communication. Such encounters activate in their participants cycles of a stress-adaptation-growth pattern. Exposure to a new, unfamiliar cultural environment, on the one hand, leads to an identity conflict, resistance to change, and the desire to retain old customs in line with the original identity. On the other hand, however, in search of harmony and equilibrium with the new milieu, individuals try to adjust their behaviours to specific situations and manage them effectively (Kim 2015).

The scholar claims (Kim 2008) that the uncertainty, confusion, and stress people experience when confronted with cultural diversity results in their activating selective attention to a new reality, its denial, avoidance, or even withdrawal. However, negative emotions can also be a driving force presenting individuals with the opportunity to search deep within for new possibilities to recreate themselves. Over time, conflict between the old and the new renders individuals susceptible to external influences and compels them to learn new cultural elements. In the process of adaptation, people attempt to gain "an overall person-environment "fit", a congruence between their internal conditions and the conditions of the new environment" (Kim 2008: 363). What they finally achieve is psychological growth - "an increased complexity in an individual's internal communication system" (Kim 2015: 5).

New identity emerges as a continuous interplay of two interwoven processes: acculturation and deculturation. The former is viewed as the learning/acquisition of new ideas, values, and cultural patterns and practices (construction). The latter involves unlearning of communication patterns developed at home and accommodating to the dominant patterns abroad and involves questioning, suspending, or rejecting, at least temporarily, some of the old cultural elements and practices (deconstruction). On the surface, the evolution individuals undergo 
can be manifested by changes in their music, food, and dress choices; and on a deeper level - by shifts in their social role-related behaviours and fundamental values, e.g., their perception of what is right or wrong (Kim 2015).

Kim notes that intercultural adaptation occurs cyclically, in a series of leaps, and is characterized by the overall forward and upward movement toward greater adaptation and growth, i.e., meeting the demands of the host environment. It is noteworthy to consider that the process varies from individual to individual, depending on their predispositions, preexisting needs, intentions, and commitment. If everything works well, in the course of adaptation an individual develops an intercultural identity - a hybrid that synthesizes components of a range of people's cultural backgrounds, "an expanded and more flexible definition of self" (Kim 1995: 178).

What is characteristic of intercultural identity is a new type of intertwined "us-other" relationship which includes two key patterns: individuation and universalization. The former capability allows for going beyond stereotypes and social categories, such as culture or ethnicity, and seeing individuals as unique entities rather than group members. The latter, i.e., a universal sense of self, locates universal, common humanity in people rather than focuses on differences (Pitts 2016). Kim argues that conceptually intercultural identity overcomes the simplistic categorization of people on the basis of stereotypical understanding of cultural differences, helps to see the common features of humanity among different cultures and ethnicities, and presents human beings as both individuals and collective human wholes (Kim 2008). Through individuation and universalization, individuals "cultivate a mindset that integrates rather than separates cultural differences" (Kim 2015: 7). In the researcher's view, individuals with well developed intercultural identity "relate to others in a less categorical and more individuated/universalized way, which allows them to create an outlook on life that transcends the parameters of any given cultural tradition" (Kim 2015: 9). They try to maintain close home cultural links, but simultaneously are willing to engage with people who come from diverse cultural backgrounds, immerse themselves in those cultures, approach cultural differences in an unbiased manner, and have positive attitudes toward differing cultural values.

\section{Research study}

\subsection{Rationale, setting, and aim}

The impetus for the study came from the author's interest in examining factors which might contribute to an increase in an individual's intercultural growth, making cross-cultural communication easier and successful. The research project, 
carried out in the academic year 2016/17, was meant to examine sojourning students' experiences during their one semester stay abroad in Poland, within the framework of the Erasmus+ program. The research aimed to get insights into the nature of the study participants' experience of studying and living in an international environment. It focused on how residence abroad impacts the individual's self analysis of their own cultural makeup, resulting in a better understanding of their own cultural backgrounds. It explored their adaptation process and how their identities evolved toward being more intercultural, i.e., the transformative opportunities that the short-term sojourn created for them.

This exploratory study sought to investigate and was guided by the following three specific research questions:

1. What were the students' expectations about studying abroad?

2. What opportunities for meaningful interactions did the study participants have, both inside and outside the university?

3. How and to what extent did the sojourn change the students, facilitating their adaptation and personal growth?

\subsection{Methods, instruments, and participants}

Given the complex nature of both the phenomenon being studied and the research questions, a qualitative approach was adopted: two rounds of semi-structured interviews were conducted at the beginning (Appendix 2) and the end of the sojourn (Appendix 3) respectively. The interviews allowed for tracking the participants' experiences in a more direct way, exploring the dynamics of their experiences and identity development. In addition, the participants were asked to fill in a short questionnaire in English at the first meeting with the researcher; i.e., before the first interview. The questionnaire aimed to establish their profiles and secure information about the following: biographical information, language background, accommodation, the extent of English usage, self-assessment of English proficiency, and comfort levels in using this language (Appendix 1). A variety of question types were used to elicit the information including multiplechoice questions, filling in the blanks, and open-ended questions.

Target recruitment and purposeful sampling recommended for qualitative research were utilized because of their ability to generate in-depth knowledge from a small but information-rich group of informants (Morse 1991). Participants were chosen from the Erasmus+ database at one large, flagship university in a large city with half a million inhabitants, in Central-West Poland. The student body at the university is very homogeneous, consisting of a very low number of international students $(3,69 \%)$, which rendered access to potential research participants difficult. The author decided to investigate Turkish students for practical reasons - their population at the time when the 
study was being designed was relatively large. At the beginning of October 2016, the author sent an invitation letter to Turkish students who had just come to Poland in the frame of an Erasmus+ grant program to study, explaining the rationale, goals, assumptions, and procedures of the study, asking them to participate in it. In the letter, it was indicated that the research would consist of four parts: a questionnaire, two personal interviews (at the beginning and at the end of the sojourn), and a diary study. The students were informed they would not receive any compensation for their participation in the study. The letter was emailed to all Turkish students listed in the university Erasmus+ database $(\mathrm{N}=83)$. It seemed to be a challenge to find participants willing to take part in a long-term project. The response rate was very low - only 5 of the students (6\% of the population) who had been invited to participate in the research responded and agreed to partake in it. Such a small response made the researcher adopt a case study approach.

The sample of 5 interview participants varied across the attributes of gender, age, and level of studies, thus, the logic of purposive sampling was followed (Corbin \& Strauss 2007; Silverman 2013). The demographics of the interviewees included a close to equal gender split with 3 females and 2 males. The ages of the participants ranged from 20 to 24 . Almost half of the sample included graduate students (2), while the remaining participants were undergraduates (3). Their majors ranged from English, international relations, and psychology (2 students), to public governance. The students came from a range of universities in Turkey: Ankara, Cumhuriyet, and Istanbul ( 3 students). All the participants were raised in monolingual Turkish families and were unfamiliar with the researcher who was to carry out the interviews.

The cohort began their sojourns with documented intermediate proficiency in English, either B1 (one student) or B2 (4 students) according to the Common European Framework of Reference for Language; i.e., high enough to be able to participate in courses, lectures, and seminars in English. Only one participant reported having knowledge of another foreign language in addition to English; i.e., German, at the level of A2.

\subsection{Data collection and procedures}

The data comes from two rounds of semi-structured interviews carried out in English, respectively at the beginning and the end of the sojourn. The choice of questions for the interview was guided by the chosen theoretical framework, i.e., Kim's model of intercultural adaptation. Since none of the participants kept a diary throughout their residence in Poland, even though they had been asked to do so and initially had agreed, there was no other data concerning their experiences available than that from the interviews. 
The interview questions were piloted with one student from the target population, prior to the interview, to check for clarity, which resulted in a few changes in their wording to resolve the ambiguities. Both interviews were conducted by the author himself - the first round in the last week of October 2016, the second, in mid-February 2017, shortly before the participants' departure. The interviews were recorded and transcribed verbatim. In order to keep the identity of the participants anonymous, their names were replaced by symbols (from S1 to S5; S1 and S2 representing the two male students). Recording allowed an in-depth analysis of the manner in which the students' stories were told and the tone of the comments. The scripts were coded for units of meaning. Such procedures were employed to follow the rigour demanded in qualitative research and to achieve more valid findings. The interviews took place individually, in a quiet room at the university venue where the author is employed. The interviews took from 35 to 60 minutes collectively, totaling 358 minutes $(\mathrm{M}=35.8 ; \mathrm{SD}=6.61 ; \mathrm{CV}=18.47 \%)$.

The first interviewing protocol revolved around 16 closed and open questions related to the students' pre-departure stage and their initial experiences. The questions were supposed to guide both the interviewer and the students. To avoid response bias (students offering acceptable responses) and overdirectiveness, the students were prompted to add their comments freely during the interviews, and make digressions. The researcher followed the participants' lead whenever they showed such initiative. First, the respondents were asked about the reasons why they decided to study abroad, their knowledge of/associations with Poland and Polish culture, and their preparation before their sojourn; i.e., whether or not they tried to learn anything about the country, its inhabitants, and culture. Second, the interviewees were queried about their prior intercultural experience, whether they travelled independently before participating in the Erasmus+ program, or lived with or kept in touch on a regular basis with an individual from a diverse culture. This question referred to contacts with both people from different countries and Turks from diverse socio-cultural, religious, and ethnic groups. This question was designed to eliminate from the sample individuals with close and regular intercultural contacts prior to their sojourns. The interviewer was also interested in whether or not the participants had received any intercultural training prior to their departure.

Another set of questions dealt with the students' initial experiences after arrival. In order to determine the study participants' access to meaningful interactions with members of the host culture, other international students, and people from socio-cultural, religious, or ethnic identifications different from their own, the interviewees were asked to report the length of time they may have spent with each group. Seven questions about students' experiences at the initial stage of their residence in Poland were meant to explore their intercultural 
awareness and learning. The questions from this group also asked whether the informants suffered from culture stress - the interviewees were prompted to discuss any incidents during their sojourns which resulted from those involved in them having different cultural assumptions.

The second set of interview questions consisted of 15 questions, both closed and open. They were meant to estimate the time the respondents had spent with representatives of the host community, determine any impediments to establishing/ developing such contacts, get information about any incidents the students had experienced and their attempts to adapt to the new cultural setting. The participants were queried about the differences they noticed between the two countries and the way classes at the university in both countries were organized and run. Further, the researcher asked the students what they had learned about themselves and how the study abroad had affected their self-confidence and selfimage. The final question concerned the shifts in their identities which the respondents had noticed and what, in their view, had contributed to them.

\subsection{Data analysis}

Initial coding was accomplished through line-by-line reading of each transcript. Within each line (or lines), words, phrases, and passages that captured the participants' sojourn experiences were identified. Coding allowed for distinguishing the key thematic categories that reflected students' sojourn experiences. Data were analyzed in several steps following the principles of a constant comparative analysis method to check for the fit between code and category, conceptual similarity, and distinctiveness among and between codes, to assess the appropriateness of their placement within, and relationships to thematic categories (Rice \& Ezzy 1999). This allowed for selecting, labelling, and grouping units of data in a way that informed the current research purpose and questions (Baptiste 2001). The emergent data and categories were considered through the lens of Kim's framework discussed in the theoretical part of the article. Two arenas were investigated, the classroom and the social contexts outside the university. The established categories were grouped into the following themes:

a) aspirations and expectations of the sojourn

b) pre-departure perception of the host country

c) initial sojourn experiences

d) host environment and in-stay experiences

e) positive reframing, adaptation and personal growth. 


\section{Findings}

The analysis of the interview data is presented according to the research questions and the themes identified at the data analysis stage discussed earlier.

\subsection{Aspirations and expectations of the sojourn}

The students decided to participate in the Erasmus+ program for a range of reasons: they wanted to travel abroad (2 students), to become acquainted with European culture ( 3 students), and increase their self-confidence ("first time in my life I live on my own and have to make decisions and rely on myself" [S1]). The participants hoped to improve their English, mainly speaking skills (3 students), by using it extensively both at the university and outside of it, and to accumulate valued symbolic capital; i.e., language, education, and friendship. In the students' view, a good command of English was supposed to give them upon return an identity as competent users of the English language (language brokers (Norton 2013)) and the prospect of an attractive career, which, they hoped, would guarantee them a high social status and respect.

The participants were aware that English was used in Poland as a lingua franca and did not aspire to uptake English culture that comes with using the language in the target community/ies. In addition, they realized that English would be a means to form relationships, access social networks, and interact with the local community and fellow Erasmus peers from a range of countries (research question 1).

\subsection{Pre-departure perception of the host country}

The case study participants chose Poland mainly for economic reasons, assuming that life here was cheaper than in other European countries. Prior to the departure they had received neither survival Polish classes, lectures on the Polish educational system and culture, nor intercultural training. The sojourners seemed to have embarked on the trip largely ignorant of what they would find in the host country. They all searched for information about Poland through the internet resources and asked their friends who had studied here before for some tips. However, their knowledge was very limited and reduced to single images and stereotypes, such as, for example: the younger generation respects the old, Polish people are religious and regularly participate in religious worship, they are nice, helpful to strangers, and like eating meat, the weather is cold and the Polish education system is very good, whereas the Polish language is very difficult to learn. One of the interviewees admitted: "I did not have much of a pre-conceived image of life in Poland" [S5], and we can assume that it was true about the whole group. 


\subsection{Initial experiences}

The interviewees began their first visit abroad excited and curious about the opportunity to personally experience the "otherness" they associated with Poland and Polish society. They were all very positive about what life in the host country would bring them. They had to create new connections and adjust to an unfamiliar cultural and linguistic environment. However, upon arrival, these young people felt stressed out, nervous, isolated, and alienated. They felt some disconnect and cultural strain, and, to a certain extent, experienced emotional turmoil since they had left their comfort zones:

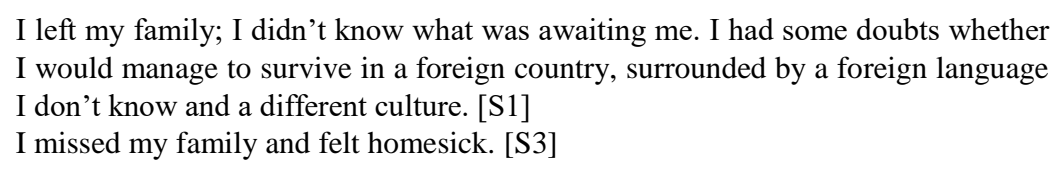

They underwent stress mainly because of the demands of studying in a different cultural and educational context. The participants reported classes were more interactive than in Turkey and that they had not been equipped with independent study skills and a critical approach requisite for studying in a European university. Education in Turkey involves a more passive absorption of knowledge, dependence on authority, repetition, and uncritical acceptance of the presented knowledge. Thus, some of the practices the students met at the university in Poland they attended questioned their habitus, i.e., "more or less permanent ways of being and behaving" (Kramsch 2009: 112), destabilizing their identity.

The English language posed a further challenge for the students - they had to struggle not only with daily communication, but also with the academic genre and specialist terminology typical of the discipline they studied. Although the university they attended did not afford the sojourners any direct support from academic advisors or foreign language instructors, nor the chance to experience new social spaces, most participants perceived studying in Poland as an opportunity to be liberated from the limitation of Turkish academic culture. Their narratives suggested that they were very critical of their prior educational experience, especially of the lack of independent learning opportunities, group work, and problem-solving. The students conceded that the stress they had experienced at the beginning of their sojourn could partially have been mitigated if they had received an orientation course prior to the departure. These findings echo the earlier works on the lived experiences of sojourners (Gill 2007; Kinginger 2013b; Tian \& Lowe 2014).

The collected data demonstrated that the academic goals of the sojourn were generally met - the participants expressed satisfaction with the programme they 
were offered at the host university. As for the English language, although they all improved their proficiency, some of them had hoped to achieve more fluency through speaking only English, which they did not do. The participants experienced a significant gap between their expectations concerning engagement with locals and the reality of establishing social networks with them, either due to contextual/situational circumstances or their own choices, which confirms Pitts' study results (2009). Erasmus students were grouped together in classes ("Half of my class constituted other Turkish students" [S2]) and dormitory rooms were distributed by university administration staff by nationalities (only one female participant had a Polish roommate). Although the respondents were wellreceived and accepted for who they were at their university, creating meaningful social ties was very challenging for them. This was not only because lack of the language was a major impediment both to communicating and negotiating cultural barriers, but also because of cultural differences in friendship formation. Hence, the study participants' commitment to interact with locals was insignificant - they did not attempt to establish closer relations with Polish students, let alone Polish people from outside the university circles, and thus very rarely were they engaging with Poles in a meaningful way. This made the students passive observers of the host community, not allowing them to actively investigate the Polish way of life.

The extent to which foreigners achieve entry into social communities depends also on how open locals are to them. However, the Poles did not initiate contacts with the sojourners. Lack of communication with the host culture hindered the participants' adaptation. The sojourners were often unable to process and interpret the input they received outside the university. Admittedly, often they could only record their sense of difference without a chance to explore the input further and deeper. This, in turn, led the students to compare the unfamiliar with the familiar that reinforced an "us-them" perspective. However, not much culture shock was reported in the interviews due to the study participants' peripheral participation in the local community. Rather than suffering from acculturative stress, the students reported they had been stressed out because they missed their families and friends, and they had experienced L2 fatigue, which stemmed from the necessity to speak extensively in English, a foreign language for them.

At the beginning, the participants spent some time with fellow Polish students assigned to them on an individual basis. They provided them with orientation and support on arriving in Poland by escorting them from the airport, arranging the formalities at the dormitory and the university, and in an emergency, helping them solve problems both at the university and outside. Those Polish students, conceived of as "guardian angels" by the study participants, adopted a protective attitude toward the Turkish students and played the role of mediators between them and Polish culture, lecture rooms, and the outside world. They helped the 
sojourners overcome loneliness, a sense of disorientation, and encouraged them to experiment and experience new things abroad. Although all the interviewed students agreed that the mentors proved a boon to them, none of them managed to cultivate this relation across the residence abroad. Nor did the mentors introduce the sojourners to their circles of friends, i.e., other Poles.

The students were aware of having a status of a racial minority and being positioned as outsiders and that they stood out, calling attention to themselves. However, on arrival, they were not subjected to negative treatment resulting from social relations of power, often exercised in a host country, in contacts with foreigners and reported in other studies (e.g., Norton 2013). Accordingly, the interviewees could relate to their hosts at their university, in the dorm, and to other Polish and international students from an equal status position. Social interactions, mainly in English, that the participants engaged in both at the university and outside were not marked by inequalities of gender or ethnicity, and the lingua franca they used was not "a mechanism of social control" (Norton 2013: 141) because their interlocutors, similarly to them, used English as a foreign language, too. The sojourners had a sense of the right to speak English, even though they were aware that it was not perfect and needed improvement:

\footnotetext{
Language was the problem, but I used it all the time. I realized that Polish and other Erasmus students also had problems with English, so I never felt inferior because of my imperfect English. All in all, I'm not English, I'm Turkish. I was satisfied once I noticed I can talk in English with other people without restraints. [S1]
}

The study participants' accounts revealed that at the beginning of their sojourn they retreated into what intercultural researchers refer to as "safe havens" or "the Erasmus bubble". They spent time with their fellow compatriots and other international students, and relied strongly on each other. Interpersonal communication with the international network provided the sojourners with a sense of support and validation of their experiences. In addition, it strengthened their national identity and the "we"-"they" dichotomy, reinforcing the sense of difference they felt on arrival. They were satisfied with this status quo and did not do much to expand their social circles. This finding confirms Coleman's claim (Coleman 2015) that individuals are satisfied with the existing social networks unless circumstances make them look for new ones. Among those circles, they were fully acknowledged as independent individuals in their own right and never felt marginalized. The sojourners turned to each other not only to establish a sense of connection, but also to share information, and to get help or advice connected with the daily challenges of living abroad. However, in a range of everyday situations when they encountered Polish people, they felt discomfort caused by not knowing the local language or culture norms. The fact the majority of the Polish population aged 45+ did not speak English (until the transformation 
in 1989 Russian had been taught obligatorily at schools) made communication with them in English impossible. For practical reasons, two of the interviewed students decided to learn Polish at the host university ("I decided to learn Polish to make my life in Poland easier" [S2]; "People appreciate it if you learn their language" [S3]) (research question 2).

\subsection{The host environment and in-stay experiences}

The sojourners had to unlearn some of the patterns developed at home and to accommodate to the dominant patterns abroad. At the university they experienced a different classroom culture that involved a closer relationship with the teacher, perceived as more friendly. Compared to the Turkish educational context, the participants assessed the classes in Poland as more student-centered, smaller in the number of attendees and the atmosphere as more relaxed. They appreciated the high qualifications of teachers, the teachers' respectful attitude toward students, and teachers' efforts to encourage them to get engaged in interaction in the classroom and to study hard outside. The host university teachers were reported to have played a crucial role in helping the respondents reduce the initial stress by providing them with academic and emotional support. In addition, the participants appreciated that their professors were "more accessible to students" [S3] and "always answered their e-mails" [S1]. They also noted that teachers in Poland assign many more presentations to prepare at home and deliver in class than teachers in Turkey.

Although on the sojourn the students sustained their home preferences regarding eating or drinking, they eagerly tried traditional Polish cuisine and liked some of the dishes. The participants tried to find similarities and differences between life in the two countries. Their observations, however, were quite simplistic and external as noted in other studies (Murphy-Lejeune 2002; Mitchell 2012) - their narratives demonstrated that they had gained insight mostly into surface issues. The collected data revealed that staying mainly within the circles of other Turkish and Erasmus students led the participants to focus on differences rather than similarities, and to overemphasize national cultures and identities. This, in turn, prompted the students to compare what they had noticed with the familiar, reinforcing an essentialist approach toward Polish culture and an "us"- "them" perspective. These findings corroborate the previous research (e.g., Jackson 2015) and the claim that if students do not have opportunities for reflection and, thus, the development of a more nuanced understanding of the complexities of culture and identity, then the sojourn contributes to students' returning home with more ingrained stereotypes.

The students noted a range of positives in the new milieu, for example that transport is well organized - there are traffic rules which are obeyed ("Priority is 
given to pedestrians, when you want to cross the street, drivers stop, whereas in Turkey cars have priority" [S3]). They were all impressed by the public transport system, much better run, in their views, than the one in Turkey ("Schedules are followed and you can move easily from one location in the city to another. In Turkey schedules are not followed, transport is not as regular as here" [S1]; "In Turkey you never know when the bus will come. However, trains in Poland are much worse than in Turkey, sometimes they are overcrowded" [S2]). The study participants were mindful about how people in public transport behaved, which led them to conclude that "in Turkey people talk to each other in such circumstances, whereas in Poland they do not" [S2].

The narratives of the interviewees revealed a marked discrepancy regarding how they perceived Polish people. However, in their reports the students often resorted to national, categorical stereotyping and there were no traces of Kim's individuation (Kim 2008) discussed earlier. One of them noted: "Polish people overuse alcohol and stay out late at night. It's difficult to drink only coffee after 8 p.m." [S1], whilst for another "drinking pure vodka is strange" [S2]. One informant remarked that Turkish people are more hospitable than Poles: "when we cook something we invite our roommates to join eating the meal. In Poland it is not common" [S2]. Another student said that "Polish people are much colder and less eager to help strangers than Turkish people" [S5].

The students were curious to get an insight into Polish social practices, for example, four of them attended a Sunday service in a Catholic church. This surprised one Polish student, who thought Islam forbids its followers to participate in religious services performed in other places than mosques. One of those Turkish students declared that she had become interested in Christianity as a result of this visit. Furthermore, the interviewees attended a few social events, for example the Independence Day party, and were impressed by how Poles celebrated it; i.e., they liked parades and people dressed up in historical costumes. Consequently, the study participants learned more about Polish traditions and lifestyle: "Polish people take care of graveyards much more" [S2]; "at the beginning of a Christmas Eve dinner they broke a wafer with each other exchanging Christmas wishes. There was one extra place at the table - I thought it was for Jesus, whereas, it turned out, it was for a stranger who might knock at the door" [S3].

The students reported being intimidated by the constant attention and stares to which they were subjected by the local population outside the university, which confirms the results of other studies (Tian \& Lowe 2014):

People are scared of Muslims and distance themselves from us. You can see from their faces they don't like us. [S1]

Sometimes people stare at us strangely when we are talking in Turkish to each other. [S2]

People often looked down on me. [S5] 
This resulted in a concern over the image they presented to the "others"; i.e., one of an undifferentiated, uniform member of a Turkish community, and it posed a threat to their self-confidence. This might have been the reason for which one student did not accept an invitation to a Christmas party organized in her dormitory for Erasmus students.

In a similar vein, the study participants experienced a negative perception of their country, shared by both international and Polish students. This initial encounter with criticism was bewildering for them and widened the divide between the in-group and the out-group. The Turkish students interviewed were surprised once they discovered that their fellow international students misinterpreted Islam, and had so little knowledge about it and Turkey:

\footnotetext{
I was surprised people have such stereotypical thinking of Muslim; jokes about bomb explosions placed by a Muslim are still told. People asked me how many wives you can have in Turkey. I was surprised how untrue and inaccurate a picture of my country they have - some still think we ride camels! [S2] Polish and international students associate Muslim with danger. Nobody told me this directly, but I know this. I felt badly about it. I tried to explain to my new friends that most stereotypes about Turkey and Turkish people which circulate around are not valid - Turkey is a developed country. [S3]

One girl in the dormitory was surprised that I, as a female Muslim, did not wear a scarf. She didn't know anything about Muslim and didn't want to learn anything about it. [S4]
}

Despite the fact that the study participants were aware that they were being stereotyped and essentialized by both their fellow Polish and international students, they did not seem able to recognize that they themselves were doing the same thing in their accounts of the Polish community.

The students reported a few unpleasant incidents which took place during their sojourn. In one of the bars in the city's downtown on a weekend, one participant was kicked by a drunken man, who got angry when he realized that the study participant couldn't speak the vernacular. What surprised the student most was that "so many people were watching the incident and nobody helped me" [S2]. Another student reported an incident he witnessed - "My Turkish, dark-skinned friend for no reason was pushed in a bar by a local girl. Our Polish friends who accompanied us told us not to worry and to ignore her, claiming there are many people who misbehave" [S1]. One informant heard of a verbal abuse his Turkish friend suffered from at a bar - the man was insulted because of his Turkish look and encouraged to return to Turkey. However, these incidents, treated as unfortunate, did not result in the sojourners' developing reluctance or fear to approach Polish people. Likewise, it is difficult to assess whether or not, and to what degree, they threatened the participants' self-confidence and self-image. The collected data revealed that none of the students declared not liking Poland 
in the aftermath of being treated with disrespect or hearing about any bad experiences their fellow Turkish students had.

\subsection{Positive reframing, adaptation, and personal growth}

The data documented in the second round of the interviews demonstrated that the participants had begun to adapt to the unfamiliar environment, which, in their accounts, was manifested by blurring the line between insiders ("us") and outsiders ("them"). Cognitively, their awareness and understanding of Polish rules, norms, and practices increased, and so did their appreciation of prevailing values ("In supermarkets you have to pay extra for plastic bags, which is an element of a green policy introduced recently by the state" [S1]). In addition, the students became capable of reflecting critically on their earlier cultural judgments, going beyond stereotypes and appreciating others as individuals with unique qualities ("I was surprised that so many people in Poland, a catholic country, get divorced, whereas, according to the catholic marriage doctrine, marital bonds are indissoluble" [S1]).

Emotionally, the sojourners' effectiveness in approaching the stress arising from living in a foreign culture improved. The students seemed to achieve a functional fitness to the new cultural setting and emotional stability ("I realized I can adapt easily to diverse settings by asking questions, looking for cues or asking explicitly for help" [S4]). One of the two participants who learned Polish gained a sense of achievement and empowerment through his capacity to engage in basic interactions with the outside world. The Polish people he spent time with were no longer representatives of "them" to be distinguished from "us", but individuals who shared similar life patterns to his compatriots ("Polish people are very hospitable just as we are. I was surprised how quickly my Polish girlfriend's family accepted me and even let me stay overnight at their home" [S2].

The blurring of the boundary between "them" and "us" in the students' accounts prompted the students to reflect on their own previous experiences of the "other" and reconsider them. Students drew on their inner thoughts and feelings about their interactions with cultural others. Consequently, some stereotypes were revisited and revised. The earlier disorientation and anxieties toward Polish people gave way to an emergent capacity to empathize with their perspectives, previously incomprehensible:

The older generation of Poles who were raised in communism doesn't show tolerance toward foreigners, because they didn't have opportunities to travel abroad and contact "otherness" when they were young. [S2]

At first I was surprised supermarkets were closed at Christmas. In Turkey everything is open at holidays. Now I understand what lies behind this - workers have families and want to spend time with them. [S3] 
People are scared of Muslims because, as I realized, the media spread such negative view of us. (...) I am more mindful and therefore I can assess everything more objectively and see things in a wider context. [S4])

Toward the end of their sojourn, the informants' perception of the host country and its inhabitants changed. The Turkish students learned something about the host country's history, traditions ("I learned some Polish folk dances ("krakowiak" and "polonez")" [S2]), visited some interesting places (Cracow, Warsaw, Wrocław, Gdańsk), and gained a deeper understanding of the context in which they were based. The students' stories showed their image of Polish people was transformed from the one of homogenous aliens to individuals with more "individuated identities" (Kim 2008: 367):

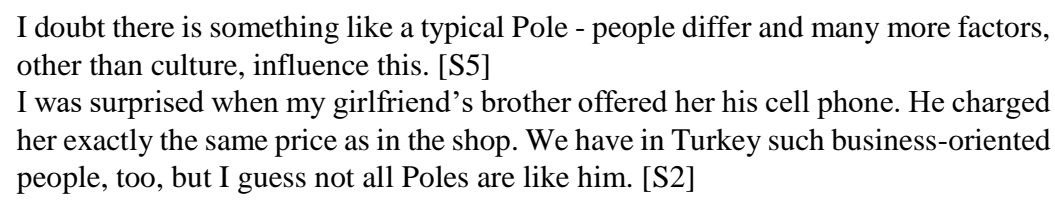

Simultaneously a more "universalized" perspective emerged in the students' accounts, which contributed to breaking the boundaries between "them" and "us", and allowed them to recognize the common nature of human beings ("Human nature is the same all over the world. Everyday life to a large extent is similar everywhere" [S5]) (research question 3).

\section{Discussion}

Analysis of the data collected from the interviews provides insightful results regarding the relevance of study abroad for participants' identity development. The narratives delineated how the current study participants gained self-insight into their own cultural makeup, starting to understand their multiple cultural identities, and how they employed their local identities to fit into the surrounding environment. The study findings concur moderately with the outcomes of the previous research in showing sojourns as a positive experience contributing to students' gaining new dimensions of their personal and social identities, and developing personal growth (Dolby 2005; Gill 2007; Kinginger 2009, 2013a, 2013b; Pitts 2009; Jackson 2010, 2015; Mitchell 2012; Kim 2014; Tian \& Lowe 2014; Czerwionka, Artamonova \& Barbosa 2015; Byram et al. 2017; Fang \& Baker 2017). On arrival, isolated from their families and the familiar cultural environment, the interviewees experienced stress, anxiety, and disorientation (the first stage of Kim's tripartite intercultural adaptation framework discussed in 
section 2), and faced a range of cultural challenges due to lack of knowledge of Polish culture, the new learning context and norms, and lack of effective preparation. To lower this discomfort in scope, students withdrew and spent most of the time with other Turkish or Erasmus students. On the one hand, in those "safe havens" they were treated as fellow compatriots, but, on the other, this isolation from the local community strengthened their sense of difference, helped them validate their national identity and reinforced the "us"-"them" divide.

The participants did not utilize the opportunity to get an in-depth insight into Polish culture by participating in it themselves due to their minute immersion in it. Thus, the degree of acculturation they managed to achieve was very limited. However, surrounded by locals in the public space and exposed to external influences and cultural challenges, the students experienced negative emotions and were forced to manage minor daily challenges they encountered. Thus, they were susceptible to learning new cultural elements and absorbing them. To a small extent, they were presented "with an opportunity for new learning and for strengthening their coping abilities" (Kim 2001: 36). In order to avoid a disequilibrium, the participants adopted a positive and open attitude toward new experiences and tried to adapt to a new cultural environment by acquiring new ideas, values and cultural practices. For example, some of them reported a willingness to become more punctual or started eating some dishes typical of Polish cuisine. In addition, they attempted proactively to accommodate themselves to the "strangeness" and to "fit into" the new learning and cultural environment.

Social engagements with other Turkish and international students allowed the sojourners a lot of reflection. The study participants tried to make the experience abroad meaningful, and they commenced creating culturally competent expectations, behaviours, and norms, initiating the process of cultural adjustment. They started to realize that both Polish culture and their own native one go beyond an exclusively national perspective. In addition, reflection enabled the participants to construct meaning from their experiences, allowing for an increase in their capacities to interact appropriately and effectively within the host society, and contributed to their achieving congruence between their internal system and the external environment (Kim 2001) (the second stage of Kim's model).

In the aftermath of encounters with culturally diverse individuals, the sojourners not only developed empathy and changed their mindsets to be more open and inclusive, but they also acquired a clearer self-understanding and started to view themselves more critically. This helped them move from the position of cultural strangers to individuals possessing intercultural personhood. The study participants were able to critically assess their own country and question some of its practices, which earlier used to be the hallmark of their self-identity ("In Turkey, close friends often criticize each other behind backs; in Poland people don't do this and I like it" [S1]). The students continued to affiliate 
themselves with the Turkish community and were proud of who they were, but developed a more complex understanding of what it meant to be Turkish.

Simultaneously, however, the sojourners began to question traditional Turkish ways of thinking and perceiving the world, and to contrast them with alternative ones. The participants acquired the capacity to critically investigate themselves and their traditions ("The drinking alcohol pattern in Turkey is strange. It's sheer hypocrisy that you can't drink alcohol with your family members, but you can do it with your friends" [S2]). In addition, the students started to position themselves beyond the national context, becoming more international and global ("I am a citizen of the world" [S4]). The new knowledge they gained resulted in a fuller understanding of the host country, which gave them the opportunity to reject their own biases and prejudices. This allowed the sojourners to see the initial bewildering experiences in a wider context and to build a positive, sometimes even enthusiastic emotional attachment to "the cultural other". Across their sojourn the participants' perception of the host community transformed from treating Polish people as alien, to offering them individualized identities. The sojourners expressed hopes to maintain the social networks they managed to establish and believed that such international contacts would enable them to keep developing more open minds, a wider perspective on life and feel more like citizens of the world:

\footnotetext{
I have friends all over the world. This summer I want to visit Georgia, where I will visit my friends I met in Poland. [S2]

I'm more mindful. I gained more self-confidence. I can assess things and people more objectively, since I try to see everything in a wider context. [S3]

I became more careful about obeying rules. I am more open to foreigners now. I realized that the extroverted part of me has become more dominant. [S5]
}

For two female participants, their sojourn helped them realize that their gendered identity as single women was constantly undermined in their home country and that women were routinely victimized by their countrymen:

\footnotetext{
In Turkey it's not easy for a girl to go out alone, you have to be careful about what you are wearing. I guess it's a stupid tradition. [S3]

I realized some Turkish traditions, such as no access for women to nightlife or a ban concerning drinking alcohol imposed on Muslims, seem to be strange and unacceptable to me. [S5]
}

The stay abroad resulted in an increase in their gender awareness and in voicing a call for gender equity. Their sojourn helped them change their mindsets and opened their eyes to a completely different worldview, i.e., the equal treatment of women, which they liked and which they declared they would try to demand upon returning home. This finding validates Kim's (2001) claim, according to which as sojourners 
achieve a closer environment-person fit, they internalize new ways of being and thinking. The study participants' accounts demonstrated that their identity began to shift from a confined one to one based more on a wider cultural identity, i.e., from Turkish to a more intercultural and inclusive one.

Although all the students reported some changes in both their attitudes and behaviours through the new experiences they had gained across their residence abroad, their extent varied. Some of the sojourners transformed more significantly than others, which depended on the degree of their immersion in the host culture. The biggest change was observed in the student who established a romantic relationship with a Polish girl and spent a lot of his time with her and her family. However, the collected data does not allow for stating unequivocally to what extent the study participants developed a sense of cultural identification that might be called intercultural; i.e., one characterized by transcending national identities and stereotypical generalizations - a lot of national stereotyping was still evident in their narratives.

Experiencing life as cultural strangers and grappling with identity conflict allowed the sojourners to feel a deeper connection with humanity and led them to reevaluate and reconstruct their selves in relation to others. This resulted in forming an integrated identity, expanded the sense of self, expressed by both individual and universal layers in their selves (Kim 2015). The development of the sojourners' identity included a new understanding of themselves in relation to the world, as well as an expanded perception of others - their identity shifted toward a more nuanced and complex Turkish identity, on the one hand, and a world citizen identity, on the other. This outcome is consistent with Dolby's (2005) and Pitts' (2009) research results.

In all the documented narratives, the students revealed becoming independent and perceived it as a crucial factor which contributed to their personal growth (the third stage of Kim's process of intercultural adaptation) and transformation in the social dimension, i.e., extending their horizons through mixing diverse perspectives. The sojourn afforded opportunities for the students' relocation, reorientation and re-rooting, rendering them more autonomous and independent (Murphy-Lejeune 2003). All the respondents talked proudly about being able to live on their own in a foreign country and cope with daily routines, such as shopping, cooking. and doing laundry, on the one hand, and more complex activities requiring problem solving, such as planning a trip abroad or travelling in Poland, on the other. All the sojourners expressed a sense of achievement and increased self-worth, which helped them build solid self-confidence. Speaking English, a foreign language for the study participants, played an important role in the development/reconstruction of their self identity, allowing them to switch "as if into an alternative mind with cultural understandings that may be at odds with their first culture" (Gill 2007: 176). 
Intercultural encounters prompted the participants to reduce the tendency to assess others and to question their stereotypical perception of culturally differing people, but concomitantly provided an impetus to contemplate their own identity, resulting in its positive reframing. The students realized that successful interactions with culturally diverse people do not necessarily require rejecting behaviours, beliefs, and values deeply embedded in their own cultural identity or compromising/reconstructing the rules for interaction prevalent in their culture. What such interactions demand is an understanding and appreciation of diversity. The sojourners declared that they were proud of their Turkish identity and that they would try to cherish some of the traditions or values in their future lives. However, at the same time some of the students started to question a few traditional Turkish values, such as the aforementioned unequal position of women in society.

It is questionable whether the process of very limited acculturation that the sojourners underwent coincided with their unlearning of the ideas and practices from the past (Kim's (2008) deculturation). What was noticed in the students' reports gathered in the second round of the interviews was the occasional questioning of Turkish cultural ideas and practices rather than rejecting them. This in fact reveals a significant shift from the participants' initial confidence in their Turkish only identity toward a more intercultural one. It is noteworthy that it seems unrealistic to expect a process of deculturation during a short-term sojourn, since students return to their home countries very shortly afterwards. In addition, it should be noted that Kim's model was proposed for the context of immigration abroad, where successful assimilation with the new cultural milieu seems to be requisite to survive. In the case of a short-term study abroad, learning new things should be perceived as adding to sojourners' cultural repertoire new elements rather than rejecting the familiar, old ones. This finding delineates some limitations of Kim's model concerning its adaptability to a short-term sojourn context.

\section{Conclusions and implications}

The collected data revealed that all the study participants underwent to a certain extent an identity shift toward "global affiliation" (Dolby 2005: 101), i.e., more open to new experiences and characterized by a greater self-other orientation. Except for language gains, i.e., developing proficiency in English, the students became more mindful and less judgmental. They advanced in personal development, gaining confidence and independence. The data provided moderate support for Kim's processes which individuals go through on the way to develop intercultural identity, namely the phases of stress, adaptation, and growth, and the concurrent processes of acculturation and deculturation. 
The acculturation to the new cultural milieu that the students managed to achieve seems to be restricted for three reasons. First, while they lived in a community of fellow Turkish and international students, their daily contact with the host community was minute and limited mainly to Polish students with whom they communicated in English. Thus, the respondents were not sufficiently immersed in the host culture. Second, the research participants did not have an instrument to contact local people - they did not know the vernacular. Even the two students who attended a language course while abroad managed to learn only "survival Polish", which did not enable them to explore the cultural practices of the local community. Third, their residence abroad was not long enough to allow for appropriation of practices dominant in the Polish community. In a similar vein, the degree of the respondents' deculturation was limited to questioning, but not necessarily suspending or rejecting beliefs, ideas, or practices of Turkish culture. Albeit the collected data did not allow for determining the scope of the reported changes, the interviewed students' narratives demonstrated that they added new cultural perspectives to the old ones, becoming more open-minded and inclusive toward diversity.

The present study is characterized by some constraints which should be addressed, since they provide the agenda for future research. First, the applied methodology, i.e., semi-structured interviews, limited and shaped to a large extent the participants' narratives. It would be good to organize a focus group with a few interviewees to discuss and investigate their lived experiences across sojourning further and deeper. Second, we cannot generalize from this smallscale case study, where, in addition, the participants self-elected to take part and probably were eager to report positively. Thus, the presented conclusions have to be regarded as preliminary and tentative. Third, the study should be replicated by complementing the data received from other than interview accounts sources, i.e., students' diaries, journals, logs, and e-portfolios. Such a triangulation of data would help investigate the nature of the adaptation process students went through and changes in their identity, validating the current study and, thereby, eventually increasing the credibility of its findings and their interpretation. Another limitation of the study is that it documented only the perspectives of the students, leaving others' points of view out of the picture. The evidence would be stronger if host university instructors and host community members carried out field observations and reported prospective changes in the sojourners. The study participants' family members could also be interviewed about changes in the sojourners. Likewise, doing similar research at different host institutions, across different countries, with a different cohort of sojourners would help check the transferability of the current study findings.

The study has clear pedagogical implications for FL education. First, language educators should recognize that residence abroad is not a magical formula 
contributing to sojourners' intercultural growth and identity change. Second, what students learn during their sojourn depends upon their participation in the host culture and abilities to focus their efforts on observations. As relevant is how they evaluate the performance of their own identity in the context they frequent, and the extent that they reflect on their lived experiences. Thus, their residence abroad should be arranged in such a way as to enable them frequent access to host communities, since only the increased contact with other cultures presents an opportunity for personal growth and adding new dimensions to individuals' identity. Third, pre-departure language and intercultural training would support students' linguistic and intercultural development during study abroad, providing them with a range of ethnographic techniques to carry out observations of a host community and instruments to cope with stress. This would alleviate students' negative sojourning experiences and help them utilize the potential of sojourns as enriching intercultural learning and transformational opportunities.

\section{Acknowledgements}

I would like to offer my sincere thanks to the participants involved in this study for their trust in my research, for without their understanding and cooperation it would not have been possible. 


\section{APPENDIX 1 - Questionnaire}

1. Gender $\mathrm{F} / \mathrm{M}$

2. Age

3. Type of studies

a) undergraduate

b) graduate

4. What do you study?

5. English proficiency (by Common European Framework of Reference for Languages):
a) A1
b) $\mathrm{A} 2$
c) B1
d) B2
e) $\mathrm{C} 1$
f) $\mathrm{C} 2$

6. Do you know any other foreign language in addition to English? If yes, what language is it and how do you assess your proficiency?

7. Accommodation in sojourn:
a) dormitory, surrounded by other Turkish students
b) dormitory, surrounded by other Erasmus+ students
c) dormitory, surrounded by local students
d) private apartment

APPENDIX 2 - Interview questions (round 1)

\section{Pre-departure}

1. Did you travel abroad individually before participating in the Erasmus+ program? How often? Where? Did you keep in touch with a person / people from different cultures before? If yes, how often?

2. What were the reasons for your participating in the Erasmus+ program?

3. Did you have any associations with the host country / inhabitants before the departure?

4. What did you know about the host culture? Did you try to learn about the country, its inhabitants, culture, etc.? If yes, where did you get the information from?

5. What did you expect to experience in the host country? 
6. Did you take part in intercultural training prior to the departure? If yes, what did you learn there and did the training prepare you for life in a diverse cultural context?

7. How did you feel before arriving to the host country?

\section{Initial experiences}

1. How did you feel upon arrival to the host country? To what extent did your pre-conceived image of your life there affect how you felt?

2. Did you experience cultural shock? If yes, what did you do to overcome it?

3. Who did you spend most of the time with after arrival? How much time did you spend with local students / people? What were the greatest impediments to establish relation with local people?

4. What were your initial experiences in the host country? Did you notice a sense of difference between life there and in Turkey / behavior of you and local people? Did you often compare the behavior of local people with a typical behavior of a Turkish citizen? How did this difference affect your communication with local people/ behavior?

5. How did local people treat you, both at the university and outside? Were you surprised / shocked by anything? Describe any positive / negative experiences.

6. Did you ever find yourself in a situation you didn't understand the behavior of a local interlocutor? Did anything go wrong when you encountered cultural differences? If yes, how did you respond?

7. What image of a Turkish person did you try to show to local people/ peers?

8. Did you do anything to adapt to the new environment and make your life easier? If yes, what was it? Did your English proficiency help you in it?

9. How did your initial sojourn experience affect your self-confidence and selfimage?

APPENDIX 3 - Interview questions (round 2)

\section{In-stay experiences}

1. Who did you spend most of the time in the host country with? How much time did you spend with local students / people? Did you feel comfortable with them?

2. To what extent did you want to fit in the host environment? How well did you manage to adapt to the new environment? Did your English proficiency help you in it? 
3. What were the greatest impediments to establish relations with local people? Did you have to get rid of some old habits (e.g. choice of music, food, dress), behaviors or values typical of your culture to adopt to life in the host country?

4. Did you notice differences between life in the host country and Turkey / your behavior and the one of local people / a system of values dominant in both countries, etc.? Did you often compare the behavior of local people with a typical behavior of a Turkish citizen? How did this difference affect your communication with local people/ behavior?

5. Did you ever find yourself in a situation you didn't understand the behavior of a local interlocutor? What did not go well when you encountered cultural differences and how did you respond? What did you learn from this experience?

6. Were you an ambassador of Turkey while abroad? What image of a Turkish person did you try to show to local people / peers?

7. How did local people perceive your cultural identity? How did they treat you, both at the university and outside? Did you have any positive / negative experiences in this respect? Were you surprised / shocked by anything? Describe any misunderstandings you experienced.

8. How is studying in the host country different from studying in Turkey?

9. What did you learn about the host country and its inhabitants?

10. How did the sojourn affect your self-confidence and self-image?

11. How strongly do you identify with Turkish culture? Did the sojourn change anything in this respect? Did you become more nationalistic?

12. How do you feel at the end of the sojourn, compared with the first days abroad? What was most challenging during your staying abroad? How do you feel about leaving?

13. Are there any elements of local culture (habits, food, values, etc.) you would like to incorporate into your life? If yes, what are they?

14. How do you assess the time spent abroad? What were the biggest benefits? Do you think the experience of studying abroad will be useful in your future life?

15. Did you change as a person? If yes, how? 


\section{REFERENCES}

Allen, Heather Willis. 2010. Language-learning motivation during short-term study abroad: An activity theory perspective. Foreign Language Annals 43(1). 27-49. DOI: $10.1111 / \mathrm{j} .1944-9720.2010 .01058 . \mathrm{x}$

Anderson, Benedict. 1983. Imagined communities: Reflections on the origin and spread of nationalism. Verso.

Banks, Melinda T. \& Rajika Bhandari. 2012. Global student mobility. In Darla K. Deardorff, Hans de Wit, John D. Heyl \& Tony Adams (eds.), The Sage handbook of international higher education, Sage. 379-398. DOI: 10.4135/9781452218397.n21

Baptiste, Ian. 2001. Qualitative data analysis: Common phases, strategic differences. Forum: Qualitative Social Research 2(3). a22. DOI: 10.17169/fqs-2.3.917

Behrnd, Verena \& Susanne Porzelt. 2012. Intercultural competence and training outcomes of students with experiences abroad. International Journal of Intercultural Relations 36(2). 213-223. DOI: 10.1016/j.ijintrel.2011.04.005

Bhabha, Homi K. 1994. The location of culture. Routledge. DOI: 10.4324/9780203820551

Bochner, Stephen, Anli Lin \& Beverly M. McLeod. 1979. Cross-cultural contact and the development of an international perspective. Journal of Social Psychology 107(1). 29-41. DOI: $10.1080 / 00224545.1979 .9922671$

Byram, Michael, Irina Golubeva, Han Hui \& Manuela Wagner. 2017. From principles to practice in education for intercultural citizenship. Multilingual Matters. DOI: $10.21832 / 9781783096565$

Chen, Victoria. 2010. Authenticity and identity in the portable homeland. In Thomas K. Nakayama \& Rona Tamiko Halualani (eds.), The handbook of critical intercultural communication, Wiley. 483-494. DOI: 10.1002/9781444390681.ch28

Coleman, James A. 2015. Social circles during residence abroad: What students do, and who with. In Rosamond Mitchell, Nicole Tracy-Ventura \& Kevin McManus (eds.), Social interaction, identity and language learning during residence abroad, European Second Language Association. 33-51.

Collentine, Joseph. 2009. Study abroad research: Findings, implications, and future directions. In: Michael H. Long \& Catherine J. Doughty (eds.), The handbook of language teaching, Wiley-Blackwell. 218-233. DOI: 10.1002/9781444315783.ch13

Corbin, Juliet \& Anselm Strauss. 2007. Basics of qualitative research: Techniques and procedures for developing grounded theory (3rd edn.). Sage.

Council of Europe. 2001. Common European Framework of Reference for Language: Learning, teaching, assessment. Cambridge University Press.

Czerwionka, Lori, Tatiana Artamonova \& Mara Barbosa. 2015. Intercultural knowledge development: Evidence from student interviews during short-term study abroad. International Journal of Intercultural Relations 49. 80-99.

DOI: $10.1016 /$ j.ijintrel.2015.06.012

Davis, Bronwyn \& Rom Harré. 1990. Positioning: The discursive production of selves. Journal for the Theory of Social Behavior 20(1) 43-63. DOI: 10.1111/j.1468-5914.1990.tb00174.x

Deardorff, Darla K. 2006. Identification and assessment of intercultural competence as a student outcome of internationalization. Journal of Studies in International Education 10(3). 241-266. DOI: $10.1177 / 1028315306287002$ 
DeKeyser, Robert. 2007. Study abroad as foreign language practice. In Robert DeKeyser (ed.), Practice in a second language. Perspectives from applied linguistics and cognitive psychology, Cambridge University Press. 208-226.

DOI: $10.1017 / \mathrm{CBO} 9780511667275.012$

De Vos, George. 1990. Conflict and accommodation in ethnic interactions. In George De Vos \& Marcelo Suarez-Orozco (eds.), Status inequality: The self in culture, Sage. 204-245.

Dolby, Nadine. 2005. Globalisation, identity, and nation: Australian and American undergraduates abroad. The Australian Educational Researcher 32. 101-117. DOI: $10.1007 / \mathrm{BF} 03216815$

Du, Xuija. 2019. The impact of semester-abroad experiences on post-sojourn L2 motivation. Studies in Second Language Learning and Teaching 9(1). 117-155. DOI: 10.14746/ssllt.2019.9.1.6

Dweyer, Mary M. 2004. More is better: The impact of study abroad program duration. Frontiers: The Interdisciplinary Journal of Study Abroad 10(1). 151-164. DOI: 10.36366/frontiers.v10i1.139

Fang, Fan \& Will Baker. 2017. 'A more inclusive mind towards the world': English language teaching and study abroad in China from intercultural citizenship and English as a lingua franca perspective. Language Teaching Research 22(5). 608-624. DOI: $10.1177 / 1362168817718574$

Gertsen, Martine Cardel. 1990. Intercultural competence and expatriates. International Journal of Human Resource Management 1(3). 341-362. DOI: 10.1080/09585199000000054

Gill, Scherto. 2007. Overseas students' intercultural adaptation as intercultural learning: A transformative framework. Compare: A Journal of Comparative and International Education 37(2). 167-183. DOI: 10.1080/03057920601165512

Hall, Stuart. 1992. The question of cultural identity. In Tony McGrew, Stuart Hall \& David Held (eds.), Modernity and its futures: Understanding modern societies. Book IV, Polity Press. 274-325.

Hall, Stuart. 1997. Representation: Cultural representations and signifying practices. Sage.

Hernandez, Todd A. 2010. The relationship among motivation, interaction, and the development of second language oral proficiency in a study-abroad context. The Modern Language Journal 94(4). 600-617. DOI: 10.1111/j.1540-4781.2010.01053.x

Irie, Kay \& Stephen Ryan. 2015. Study abroad and the dynamics of change in learner L2 selfconcept. In Zoltán Dörnyei, Peter D. MacIntyre \& Alastair Henry (eds.), Motivational dynamics in language learning, Multilingual Matters. 343-366.

DOI: $10.21832 / 9781783092574-022$

Ivanič, Roz. 1998. Writing and identity: The discoursal construction of identity in academic writing. John Benjamins. DOI: 10.1075/swll.5

Jackson, Jane. 2010. Intercultural journeys: From study to residence abroad. Palgrave Macmillan. DOI: $10.1057 / 9780230277083$

Jackson, Jane. 2015. Becoming interculturally competent: Theory to practice in international education. International Journal of Intercultural Relations 48. 91-107. DOI: $10.1016 /$ j.ijintrel.2015.03.012

Kim, Sujin. 2014. New media, English language learning, and intercultural identity. TESOL Journal 5(1). 156-158.

Kim, Young Yun. 1988. Communication and cross-cultural adaptation: An integrative theory. Multilingual Matters. 
Kim, Young Yun. 1995. Cross-cultural adaptation: An integrative theory. In Richard L. Wiseman (ed.), Intercultural communication theory, Sage. 170-193.

Kim, Young Yun. 2001. Becoming intercultural: An integrative theory of communication and cross-cultural adaptation. Sage.

Kim, Young Yun. 2005. Adapting to a new culture: An integrative communication theory. In William B. Gudykunst (ed.), Theorizing about intercultural communication, Sage. 375-400.

Kim, Young Yun. 2008. Intercultural personhood: Globalization and a way of being. International Journal of Intercultural Relations 32(4). 359-368. DOI: 10.1016/j.ijintrel.2008.04.005

Kim, Young Yun. 2015. Finding a "home" beyond culture: The emergence of intercultural personhood in the globalizing world. International Journal of Intercultural Relations, 46. 3-12. DOI: 10.1016/j.ijintrel.2015.03.018

Kinginger, Celeste. 2009. Language learning and study abroad: A critical reading of research. Palgrave Macmillan. DOI: 10.1057/9780230240766

Kinginger, Celeste. 2013a. Social and cultural aspects of language learning in study abroad. John Benjamins. DOI: 10.1075/11lt.37

Kinginger, Celeste. 2013b. Identity and language learning in study abroad. Foreign Language Annals 46(3). 339-358. DOI: 10.1111/flan.12037

Kormos, Judit, Kata Csizér \& Janina Iwaniec. 2014. A mixed-method study of language-learning motivation and intercultural contact of international students. Journal of Multilingual and Multicultural Development 35(2). 151-166. DOI: 10.1080/01434632.2013.847940

Kramsch, Claire. 2009. The multilingual subject. Oxford University Press.

Lou, Kris Hemming \& Gabriele Weber Bosley. 2012. Facilitating intercultural learning abroad: The intentional, targeted intervention model. In Michael Vande Berg, R. Michael Paige \& Kris Hemming Lou (eds.), Student learning abroad: What our students are learning, what they're not, and what we can do about it, Stylus. 335-359.

Magnan, Sally Sieloff \& Michele Back. 2007. Social interaction and linguistic gain during study abroad. Foreign Language Annals 40(1). 43-61. DOI: $10.1111 / \mathrm{j} .1944-9720.2007 . t b 02853 . x$

Menard-Warwick, Julia. 2005. Both a fiction and an existential fact: Theorizing identity in second language acquisition and literacy studies. Linguistics and Education 16(3). 253-274. DOI: 10.1016/j.linged.2006.02.001

Mitchell, Kristine. 2012. Student mobility and European identity: Erasmus study as a civic experience? Journal of Contemporary European Research 8(4). 490-518.

Morgan, Brian. 2007. Poststructuralism and applied linguistics: Complementary approaches to identity and culture in ELT. In Jim Cummins \& Chris Davison (eds.), International handbook of English language teaching, Springer. 1033-1052. DOI: 10.1007/978-0-387-46301-8_69

Morse, Janice M. 1991. Strategies for sampling. In Janice M. Morse (ed.), Qualitative nursing research: A contemporary dialogue, Sage. 127-145. DOI: $10.4135 / 9781483349015 . n 16$

Murphy-Lejeune, Elizabeth. 2002. Student mobility and narrative in Europe: The new strangers. Routledge.

Murphy-Lejeune, Elizabeth. 2003. An experience of interculturality: Student travellers abroad. In Geof Alred, Michael Byram \& Mike Fleming (eds.), Intercultural experience and education, Multilingual Matters. 101-113. DOI: 10.21832/9781853596087-010 
Norton, Bonny. 2013. Identity and language learning. Extending the conversation (2nd edn). Multilingual Matters. DOI: 10.21832/9781783090563

Pitts, Margaret. J. 2009. Identity and the role of expectations, stress, and talk in short-term student sojourner adjustment: An application of the integrative theory of communication and cross-cultural adaptation. International Journal of Intercultural Relations 33(6). 450462. DOI: 10.1016/j.ijintrel.2009.07.002

Pitts, Margaret. J. 2016. Sojourner reentry: A grounded elaboration of the integrative theory of communication and cross-cultural adaptation. Communication Monographs 83(4). 419-445. DOI: 10.1080/03637751.2015.1128557

Rice, Pranee Liamputtong \& Douglas Ezzy. 1999. Qualitative research methods: A health focus. Oxford University Press.

Silverman, David. 2013. Doing qualitative research (4th edn.). Sage.

Stephenson, Skye. 1999. Study abroad as a transformational experience and its effects upon study abroad students and host nationals in Santiago, Chile. Frontiers: The Interdisciplinary Journal of Study Abroad 5(1). 1-38. DOI: 10.36366/frontiers.v5i1.70

Taguchi, Naoko. 2015. Cross-cultural adaptability and development of speech act production in study abroad. International Journal of Applied Linguistics 25(3). 343-365. DOI: $10.1111 /$ ijal.12073

Tian, Mei \& John Anthony Lowe. 2014. Intercultural identity and intercultural experiences of American students in China. Journal of Studies in International Education 18(3). 281-297. DOI: $10.1177 / 1028315313496582$

Vande Berg, Michael. 2007. Intervening in the learning of U.S. students abroad. Journal of Studies in International Education 11(3-4). 392-399. DOI: 10.1177/1028315307303924

Vande Berg, Michael \& R. Michael Paige. 2009. Applying theory and research: The evolution of intercultural competence in U.S. study abroad. In Darla K. Deardorff (ed.), The SAGE handbook of intercultural competence, Sage. 419-437.

Van Dick, Rolf, Ulrich Wagner, Thomas F. Pettigrew, Oliver Christ, Carina Wolf, Thomas Petzel, Vanessa Smith Castro \& James S. Jackson. 2004. Role of perceived importance in intergroup contact. Journal of Personality and Social Psychology 87(2). 211-227. DOI: $10.1037 / 0022-3514.87 .2 .211$

Wilkinson, Sharon. 1998. Study abroad from the participants' perspective: A challenge to common beliefs. Foreign Language Annals 31(1). 23-39.

DOI: $10.1111 / j .1944-9720.1998 . t b 01330 . x$ 